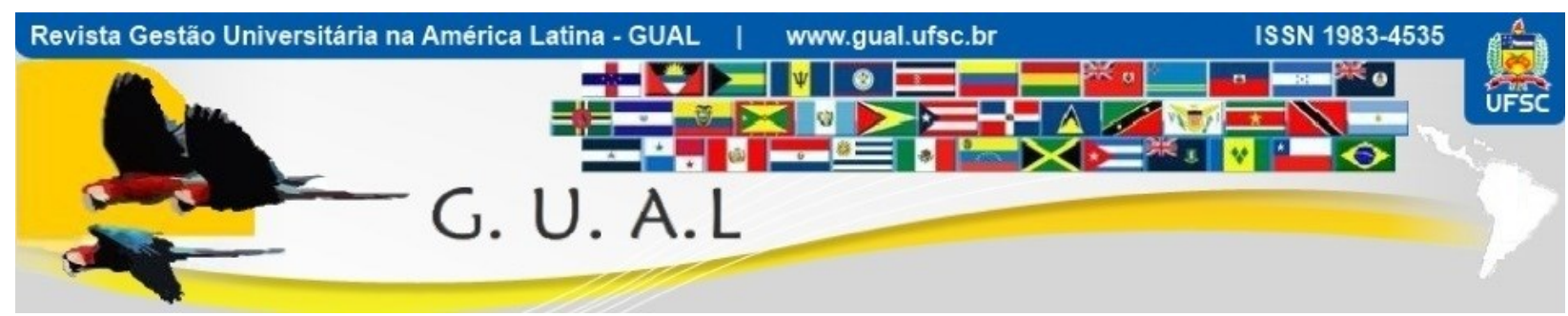

DOI: http://dx.doi.org/10.5007/1983-4535.2018v11n4p292

\title{
A SUSTENTABILIDADE NA PERSPECTIVA DE DISCENTES DE ADMINISTRAÇÃO DE UMA UNIVERSIDADE PÚBLICA FEDERAL: NA PRÁTICA A SUSTENTABILIDADE FICA NO DISCURSO
}

\author{
SUSTAINABILITY IN THE PERSPECTIVE OF STUDENTS IN THE \\ UNDERGRADUATE MANAGEMENT PROGRAM OF A PUBLIC UNIVERSITY: IN \\ PRACTICE, SUSTAINABILITY REMAINS ONLY IN DISCOURSE
}

Annor da Silva Junior, Doutor Universidade Federal do Espírito Santo - UFES annor.silva@ufes.br

Priscilla de Oliveira Martins da Silva, Doutora Universidade Federal do Espírito Santo - UFES priscilla.silva@ufes.br

Kátia Cyrlene de Araújo Vasconcelos, Doutora Universidade Federal do Espírito Santo - UFES katia.vasconcelos@oi.com.br

Vitor Correa da Silva, Doutorando Universidade Federal do Espírito Santo - UFES vitor_correa@msn.com

Sarah Luiza Martins Silva de Brito, Graduanda Universidade Federal do Espírito Santo - UFES sasaluiza@gmail.com

José Michel Rocha Monteiro, Graduando Universidade Federal do Espírito Santo - UFES michelr.monteiro@,outlook.com

Recebido em 24/novembro/2017

Aprovado em 06/setembro/2018

Sistema de Avaliação: Double Blind Review

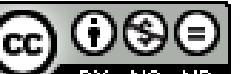

Esta obra está sob uma Licença Creative Commons Atribuição-Uso. 


\title{
RESUMO
}

Investigou-se o ponto de vista de discentes de graduação em administração acerca da noção de sustentabilidade. Articulou-se a teoria dos stakeholders, com o corpo de conhecimento acerca da sustentabilidade, da ética e da formação do administrador. Metodologicamente, realizou-se uma pesquisa survey, cuja coleta envolveu a triangulação de dados por meio da aplicação de questionários e pesquisa documental. Os dados coletados por meio de questionários foram submetidos à análise estatística. A amostra contou com 233 discentes (30,98\% do tamanho da população) de todos os períodos do curso e dos turnos matutino e noturno. A síntese dos resultados revela que, do ponto de vista dos respondentes, a noção de sustentabilidade, que pressupõe o tratamento equitativo das dimensões econômica, sociocultural e ambiental, fica apenas no campo do discurso (comportamento esperado) e não se materializa na prática (comportamento efetivo). As evidências indicam que a dimensão econômica prevalece sobre as demais, principalmente, quando a lucratividade do acionista e a sobrevivência da organização são os objetos de investigação. Reflexões acerca do processo de formação do administrador são necessárias, sobretudo pelos indícios de que o modelo de formação cartesiano e voltado para a lucratividade ainda prevalece frente a educação voltada para a sustentabilidade.

Palavras-chave: Sustentabilidade. Formação do Administrador. Stakeholders. Comportamento Esperado. Comportamento Efetivo.

\begin{abstract}
This paper investigates the perspective of students in the undergraduate Management program of a Brazilian public university regarding the notion of sustainability. It was articulated the stakeholder theory with the body of knowledge of sustainability, ethics and managers' education. As to method, a quantitative survey was carried out with data collected through triangulation with questionnaire application and documentary research. Data collected via questionnaire application were underwent to statistical analysis. The research sample reached 233 students (30.98\% of the population size) from all terms and morning and evening shifts of the course. The synthesis of results reveals that, according to the respondents' perspective, the notion of sustainability, which entails an equitable treatment of the economic, social-cultural, and environmental dimensions, remains only in the field of discourse (expected behavior), and does not manifest in practice (actual behavior). Evidence indicates that the economic dimension prevails over the others, especially when the shareholder profitability and the survival of the organization are the objects of investigation. Results refer to reflections on the process of managers' education, especially because there is evidence that the profit-targeted, Cartesian educational model still prevails over the logic of a sustainability-targeted education.
\end{abstract}

Keywords: Sustainability. Manager's Education. Stakeholders. Expected Behavior. Actual Behavior. 


\section{A SUSTENTABILIDADE NA PERSPECTIVA DE DISCENTES DE ADMINISTRAÇÃO DE UMA \\ UNIVERSIDADE PÚBLICA FEDERAL: NA PRÁTICA A SUSTENTABILIDADE FICA NO DISCURSO \\ DOI: http://dx.doi.org/10.5007/1983-4535.2018v11n4p293}

\section{INTRODUÇÃO}

Apresenta-se neste artigo os resultados de uma parte de um projeto de pesquisa mais amplo que investiga o ponto de vista de discentes de cursos de graduação em administração e em ciências contábeis e de discentes de pós-graduação lato-sensu (especialização) na área de negócios acerca da noção de ética, de responsabilidade social corporativa (RSC) e de sustentabilidade. O foco deste artigo foi investigar o ponto de vista de discentes de administração de uma universidade pública brasileira sobre a noção de sustentabilidade. Para isso, abordou-se dois temas centrais: sustentabilidade e formação educacional do administrador.

Segundo Ciegis et al. (2009), a noção de sustentabilidade está associada, num sentido mais amplo, à equidade na distribuição das possibilidades de desenvolvimento entre o presente e as futuras gerações. Em outros termos, o desenvolvimento sustentável pode ser definido como uma melhor qualidade de vida do presente e das futuras gerações. Os autores complementam ainda que, o desenvolvimento sustentável não envolve uma escolha entre a proteção ambiental e o progresso social. Está relacionado com um esforço maior para o desenvolvimento econômico e social que seja compatível com a proteção ao meio ambiente. Com isso, o desenvolvimento sustentável envolve três dimensões fundamentais, que são interdependentes e formam o triple bottom line - TBL: econômica, social e ambiental (ELKINGTON, 2012).

Nos últimos anos, conforme apontam Vasconcelos et al. (2013), Senge et al. (2009) e Almeida (2008; 2002), o ambiente de negócios vem passando por transformações em que a visão de racionalidade científica e especialização, de produção e eficácia e de competitividade sem cooperação, vem sendo substituída por uma visão holística, de integração e de síntese. Essa nova perspectiva leva em consideração um modelo baseado em uma governança tripolar que, entre outros aspectos, implica em trocas dinâmicas entre os atores econômicos e sociais com vistas ao alcance de equilíbrio entre os objetivos e resultados financeiros, sociais e ambientais, que caracterizam o modelo sustentável. Este modelo, exige das organizações uma maior interação com a sociedade e uma postura integradora de suas condicionantes internas e externas (VASCONCELOS et al., 2013; SACHS, 2008; ALMEIDA, 2008; 2002).

Como apontam Vasconcelos et al. (2013), esse modelo sustentável requer uma nova forma de concepção de negócios sustentáveis, compreendendo-os como atividades empresariais holisticamente concebidas, voltadas para o desenvolvimento econômico e social 
equilibrado nos ecossistemas locais e para a modernidade. Esses negócios possuem vocação para o longo prazo ao considerarem as necessidades das gerações futuras e ao assumirem uma postura de cooperação em detrimento da competição. Os autores apontam ainda que, para a atuação em negócios sustentáveis é necessária uma educação gerencial voltada para a sustentabilidade.

Ao se falar em educação gerencial, há que se considerar a formação do administrador, sobretudo nos cursos de graduação em administração. No Brasil, a formação educacional e a atividade profissional do administrador são regulamentadas por legislação federal que institui requisitos fundamentais para o exercício profissional, como por exemplo, a diplomação em curso de administração (bacharelado) reconhecido pelo Ministério da Educação (MEC) e o registro no Conselho Regional de Administração (CRA) (FEU et al., 2016; BRASIL, 1965).

O MEC, ao exercer o papel de regulamentar a educação superior (SILVA JUNIOR et al., 2014) edita normas jurídicas, como é o caso das Diretrizes Curriculares Nacionais (DCN) que, no caso específico da administração, foi instituída por meio da Resolução CNE/CES nº 4 de 13 de julho de 2005. As DCN estabelecem as orientações para que as Instituições de Educação Superior (IES) devidamente credenciadas junto ao MEC possam definir em seus Projetos Pedagógicos de Curso (PPC) aspectos como objetivos do curso, perfil profissional, componentes curriculares, sistemas de avaliação, entre outros (FEU et al., 2016; CNE, 2005).

Dentre os diversos conteúdos possíveis de serem abordados nos currículos dos cursos de administração, há uma orientação geral para que sejam observadas as implicações éticas do exercício profisssional. Essa orientação parece indicar a preocupação com a formação desses futuros profissionais que, ao assumirem cargos gerenciais nas organizações, tomarão decisões com implicações econômicas, sociais e ambientais para toda a sociedade.

Tendo como fundamento as preocupações acerca do processo de formação educacional de futuros administradores, sobretudo em relação à atuação em negócios sustentáveis, definiu-se o seguinte problema de pesquisa: Qual é o ponto de vista de discentes de graduação em administração sobre a noção de sustentabilidade? Com base nessa questão, definiu-se como objetivo geral o de identificar o ponto de vista de discentes de graduação em administração sobre a noção de sustentabilidade. Para alcançar o objetivo central proposto, realizou-se uma pesquisa survey de natureza descritiva e quantitativa (BABBIE, 2005) junto aos discentes de administração de uma universidade pública federal localizada na região sudeste do Brasil. 


\section{A SUSTENTABILIDADE NA PERSPECTIVA DE DISCENTES DE ADMINISTRAÇÃO DE UMA \\ UNIVERSIDADE PÚBLICA FEDERAL: NA PRÁTICA A SUSTENTABILIDADE FICA NO DISCURSO \\ DOI: http://dx.doi.org/10.5007/1983-4535.2018v11n4p293}

Estruturou-se este artigo em cinco seções além desta introdução. Na segunda seção apresenta-se a perspectiva conceitual que envolve o tema sustentabilidade e desenvolvimento sustentável. Na sequência aborda-se a questão da formação do administrador e a sustentabilidade. Na quarta seção apresenta-se os procedimentos metodológicos que nortearam o processo de coleta e de análise dos dados. Na seção seguinte discute-se os resultados da pesquisa. Por fim, na sexta e última seção, são apresentadas as conclusões.

\section{SUSTENTABILIDADE E DESENVOLVIMENTO SUSTENTÁVEL}

O conceito de desenvolvimento sustentável apresentado no Relatório Brundtland Nosso Futuro Comum", publicado em 1987, é bastante questionado por sua imprecisão e por representar um discurso liberal e redentor (MEBRATU, 1998; CIEGIS et al., 2009). Além disso, as críticas também tratam da natureza complexa, ambígua e de seu caráter corretivo, além do fato de seu escopo não tratar da interdisciplinaridade e não abordar as impossibilidades diante de um sistema capitalista (HANN et al., 2015).

As críticas aos conceitos de desenvolvimento sustentável e de sustentabilidade (termos encontrados na literatura utilizados de forma intercambiada), residem no fato de eles serem de natureza conceitual e mal compreendidos (EKINS, 2003), imprecisos (MEBRATU, 1998; SARTORI et al., 2014), otimistas e vagos (PAUL, 2008), multidimensionais (PIERANTONI, 2004; CIEGIS et al., 2009; MÜLLER; PFLEGER, 2014 ), difíceis de serem operacionalizados e questionáveis quanto ao potencial de viabilização de mudança (FERGUS; ROWNEY, 2005). Além disso, são criticados pela natureza dual (CIEGIS et al., 2009) e por conterem sobreposições de conceitos e estratégias (FERGUS; ROWNEY, 2005).

No âmbito das críticas, o que se argumenta é que a sustentabilidade e o desenvolvimento sustentável apregoados pela visão tradicional são de natureza compensatória, reduzindo-se a práticas que preservam a imagem externa de uma organização, que trabalham a favor de um sistema capitalista, gerando uma falsa noção de conciliação entre capital e natureza, de forma que o sistema "tenha direito de ter o seu bolo e possa comê-lo" (LELE, 1991, p.618). Por outro lado, Sartori et al. (2014) argumentam que, a despeito das críticas, da imprecisão e da falta de consenso quanto aos conceitos, é possível identificar que há em comum: (1) a preocupação em passar para gerações futuras o estoque de capital; (2) tratam de valores coletivos; (3) tratam de escolhas; (4) requerem exercício da ética coletiva em detrimento ao individual. 


\section{A SUSTENTABILIDADE NA PERSPECTIVA DE DISCENTES DE ADMINISTRAÇÃO DE UMA \\ UNIVERSIDADE PÚBLICA FEDERAL: NA PRÁTICA A SUSTENTABILIDADE FICA NO DISCURSO \\ DOI: http://dx.doi.org/10.5007/1983-4535.2018v11n4p293}

No debate sobre os dilemas da transição para um mundo sustentável, Le Roux e Pretorius (2016) e Müller e Pfleger (2014) argumentam que o modelo de desenvolvimento que leva em consideração o equilíbrio nas dimensões econômicas, sociais e ambientais é desafiador, na medida em que a execução paralela dos pilares econômicos, sociais e ambientais, podem suscitar conflitos. Esses conflitos estão relacionados ao fato de ainda haver um predomínio das decisões baseadas exclusivamente na dimensão econômica, fazendo com que as outras dimensões deixem de ser consideradas (LE ROUX; PRETORIUS, 2016; MÜLLER; PFLEGER (2014). Sob esse aspecto, Hann et al. $(2015 ; 2010)$ argumentam que, dada a natureza multifacetada e complexa do desenvolvimento sustentável, os trade-offs e conflitos são a regra, e não a exceção, na medida em que o modelo traz tensões para as organizações.

\section{FORMAÇÃO DO ADMINISTRADOR E A SUSTENTABILIDADE}

Autores como Feu et al. (2016), Boava et al. (2014) e Alcadipani e Caldas (2012) têm se dedicado a discutir as questões que envolvem os cursos de graduação em administração, sobretudo, com vistas a abordar aspectos relativos ao processo de formação educacional e a atuação profissional. Por exemplo, Alcadipani e Caldas (2012) analisaram o processo histórico dos cursos de administração no Brasil e destacaram a influência que esses cursos sofreram em relação às orientações anglo-saxônicas das escolas estadunidenses. Esta influência foi responsável pelo viés funcionalista e positivista presentes nos cursos e, consequentemente na formação dos administradores (BOAVA et al., 2014; ALCADIPANI; CALDAS, 2012).

Conforme apontam Boava et al. (2014), os currículos dos cursos de administração têm como foco a superestrutura funcional da área, inibindo os discentes ao acesso às disciplinas críticas e reflexivas que possibilitam o desenvolvimento de competências e habilidades do administrador. Em outros termos, há um foco maior em disciplinas (de natureza funcionalista) como marketing, gestão de pessoas e finanças, ao passo que disciplinas (de natureza crítica e reflexiva) como filosofia, criatividade e desenvolvimento de ideias, têm sido negligenciadas.

Dentre as disciplinas consideradas críticas e reflexivas, destacam-se aquelas que abordam as temáticas da ética, da RSC e da sustentabilidade. Conforme apontam Jacobi et al. (2011), a introdução dessas temáticas no curso de administração ocorreu por meio de pressões do meio empresarial e da sociedade no sentido de que as preocupações com aspectos 


\section{A SUSTENTABILIDADE NA PERSPECTIVA DE DISCENTES DE ADMINISTRAÇÃO DE UMA \\ UNIVERSIDADE PÚBLICA FEDERAL: NA PRÁTICA A SUSTENTABILIDADE FICA NO DISCURSO \\ DOI: http://dx.doi.org/10.5007/1983-4535.2018v11n4p293}

socioculturais e ambientais fossem tratadas na formação dos futuros administradores. Segundo os autores, as discussões sobre a sustentabilidade ancoram-se no conceito do TBL (ELKINGTON, 2012) que pressupõe equidade na performance econômica, social e ambiental.

Ao analisarem e proporem o conteúdo básico para o ensino de sustentabilidade no curso de administração, Hourneaux Junior et al. (2014) destacam que as IES abordam a questão da sustentabilidade por meio de abordagem clássica que envolve a mera inserção do tema nas grades curriculares sem integração com outras disciplinas. Para os autores, esta forma de inserção não é considerada como ideal, visto que a sustentabilidade é um tema transversal que deveria ser tratado de forma integrada com as outras disciplinas do curso.

Gonçalves-Dias et al. (2013) realizaram um estudo em que constataram os desafios enfrentados pelas IES para a implementação de PPC que privilegiem modelos de ensino e aprendizagem voltados para a sustentabilidade. Os autores apontam que abordar a sustentabilidade nos cursos de administração requer mais do que repensar os conteúdos curriculares. Exigem das IES compromissos mais profundos que envolvam uma agenda institucional em que o "aprender sustentabilidade" transcende o ensino propriamente dito, para alcançar também o aprender e a atuação coletiva, ou seja, assumir a sustentabilidade como algo cultural e institucionalizado (SCHVARSTEIN, 1995) na dinâmica da comunidade acadêmica.

No conjunto dessas contribuições (HOURNEAUX JUNIOR et al., 2014; GONÇALVES-DIAS et al., 2013; JACOBI et al., 2011), constata-se que a perspectiva clássica, tradicional e cartesiana presente no processo de educação gerencial não é compatível com a abordagem do modelo de educação para a sustentabilidade. Neste caso, faz-se necessário adotar uma visão e abordagem para a sustentabilidade em que a perspectiva holística, de integração e de síntese norteie o processo de formação educacional nos cursos de graduação em administração, inclusive na postura das instituições (VASCONCELOS et al., 2013; SENGE et al., 2009; ALMEIDA, 2008; 2002; ANTONELLO, 2005).

\section{MÉTODO}

Metodologicamente a pesquisa caracteriza-se como um estudo descritivo-quantitativo, a partir do método de pesquisa survey (BABBIE, 2005). Os dados foram coletados por meio de triangulação (DENZIN, 1989; JICK, 1979) ao combinar dois procedimentos: pesquisa documental e aplicação de questionário. A pesquisa documental foi realizada junto as DCN 
do curso de administração (CNE, 2005), aos PPC do curso de administração (turnos matutino e noturno) e aos dados estatísticos fornecidos pela pró-reitoria de graduação, pelo departamento de administração e disponíveis no sitio eletrônico da IES e do curso.

O questionário foi desenvolvido, submetido a pré-teste e validado especificamente para esta pesquisa. Para a elaboração do questionário, fez-se uso de trabalhos consolidados na literatura acerca do tema sustentabilidade e da teoria dos stakeholders, tais como as contribuições Elkington (2012), Purnell e Freeman (2012) Ciegs et al. (2009) e Pierantoni (2004). Assim, o questionário considerou as três dimensões do TBL, quais sejam: econômica, sociocultural e ambiental (ELKINGTON, 2012) e um conjunto de stakeholders (PURNELL; FREEMAN, 2012). Ademais, para a construção do questionário, considerou-se a lógica da duplicidade moral tipicamente brasileira (SROUR, 1994), ou seja, o comportamento esperado das pessoas (relacionado à moral da integridade) e o comportamento efetivo (relacionado à moral do oportunismo).

O questionário foi composto por duas partes, sendo que a primeira se dedicou a identificar o perfil sociodemográfico dos respondentes e a segunda estava relacionada com os objetivos da pesquisa. Esta segunda parte foi composta por 42 afirmativas em escala Likert de cinco pontos, sendo 21 que caracterizavam o comportamento esperado e 21 que caracterizavam o comportamento efetivo. Cada grupo de 21 afirmativas era composto por 7 afirmativas de cada uma das três dimensões do TBL (ELKINGTON, 2012). Ressalta-se também que cada uma dessas 7 afirmativas estava relacionada a diferentes stakeholders, quais sejam: acionistas, empregados, fornecedores, consumidores, concorrentes, sociedade e meio ambiente.

A população de interesse do estudo foi a de alunos da graduação em administração de uma universidade pública federal localizada na região sudeste do Brasil. O curso funciona nos turnos matutino e noturno e a amostra da pesquisa contou com 233 respondentes $(30,98 \%$ do total da população de 752 discentes vinculados ao curso) que estavam distribuídos em todos os períodos do curso. Considerando a aleatoriedade do método de amostragem, pode-se inferir por meio de um cálculo para populações finitas que os resultados da pesquisa possuem um nível de confiança de 95\% com uma margem de erro de 5,5\% (LEVINE et al., 2015).

Para testar a confiabilidade do questionário, especialmente em relação aos construtos "comportamento esperado" e "comportamento efetivo", utilizou-se o alfa de cronbach e a análise fatorial pelo método de análise de componentes principais. O alfa de cronbach para o 
conjunto de afirmativas que caracterizavam o comportamento esperado e o comportamento efetivo foi de 0,877. Considerando que ambos foram superiores a 0,7 , pode-se inferir que ambos os construtos apresentaram um adequado nível de confiabilidade (FÁVERO et al., 2009).

A respeito da análise fatorial exploratória, observou-se que a estatística KMO (KaiserMeyer-Olkin) apresentou o valor de 0,873. Conforme Fávero et al. (2009), este valor pode ser considerado como adequado. Adicionalmente, o teste de esfericidade de Barlett foi significativo a $1 \%(\mathrm{p}=0,000)$, aspecto que também sugere a adequação da análise fatorial (FÁVERO et al., 2009). Dez fatores puderam ser extraídos com autovalores maior que 1. Porém, ao se observar o gráfico Scree apresentado na Figura 1, pode-se notar que dois deles possuem uma capacidade de explicação da variância total consideravelmente maior que os demais. Presume-se que estes dois fatores representem os construtos "comportamento esperado" e "comportamento efetivo".

\section{Figura 1 Gráfico Scree}

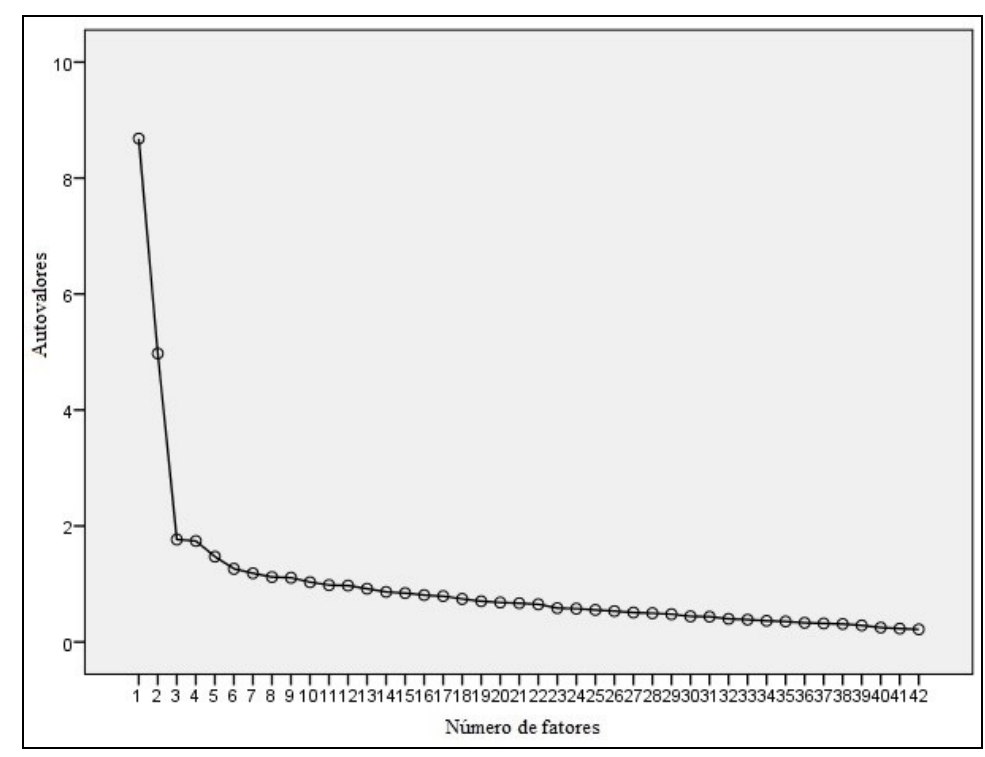

Após a observação de que dois fatores seriam mais relevantes para a explicação do total da variância, procedeu-se à análise fatorial para a identificação de dois fatores. A partir da matriz de componente rotativa dessa análise fatorial (método varimax com rotação ortogonal), verificou-se a adequação dos itens dos questionários aos construtos esperados. $\mathrm{O}$ valor de 0,35 (em valores absolutos) foi utilizado como corte nas cargas fatoriais, visto que a amostra da pesquisa se aproximou de 250 respondentes, valor de corte indicado como 


\section{A SUSTENTABILIDADE NA PERSPECTIVA DE DISCENTES DE ADMINISTRAÇÃO DE UMA \\ UNIVERSIDADE PÚBLICA FEDERAL: NA PRÁTICA A SUSTENTABILIDADE FICA NO DISCURSO \\ DOI: http://dx.doi.org/10.5007/1983-4535.2018v11n4p293}

adequado para este tamanho amostral (FÁVERO et al., 2009). Do total de 42 itens, 37 $(88,09 \%)$ apresentaram carga fatorial maior que $0,35 \mathrm{em}$ valores absolutos. Todos estes 37 itens se associaram corretamente com o fator esperado na elaboração do questionário. Este aspecto sugere uma adequada confiabilidade para os construtos "comportamento esperado" e “comportamento efetivo".

Após a identificação da confiabilidade do instrumento de pesquisa, procedeu-se à análise de distribuição de frequências das afirmativas em escala Likert. Ressalta-se que todos os procedimentos estatísticos foram realizados por meio do software SPSS versão 22.

\section{APRESENTAÇÃO, ANÁLISE E DISCUSSÃO DOS RESULTADOS}

Estruturou-se esta seção em três partes. $\mathrm{Na}$ primeira parte são apresentadas as considerações acerca do curso de administração. Na segunda apresentam-se os dados sociodemográficos da amostra da pesquisa. Por fim, na terceira parte aborda-se os resultados relativos ao ponto de vista dos discentes em administração em relação à sustentabilidade.

\subsection{O CURSO DE ADMINISTRAÇÃO}

O curso de administração da IES foi criado na década de 1960, inicialmente funcionando apenas no turno matutino. No final da década de 2000, o curso passou a ser ofertado também no turno noturno. Do ponto de vista formal, o curso possui um PPC para o turno matutino e outro para o noturno. Cada PPC possui definições sobre o perfil do egresso, objetivo do curso, estrutura curricular, entre outros aspectos. Em relação ao perfil do egresso, os PPC dos dois turnos destacam o compromisso do curso em trabalhar junto aos discentes a internalização de valores de responsabilidade social, justiça e ética profisssional, uma sólida formação humanista e visão global, além de sólida formação técnica e científica.

Embora os PPC tenham a mesma definição de perfil de egresso para os dois turnos, constatou-se que as estruturas curriculares são diferentes, sendo que o turno matutino é composto por 8 módulos que podem ser integralizados em 4 anos; e o turno noturno possui 9 módulos que podem ser integralizados em 4,5 anos, ambos podendo ser estendidos por no máximo mais dois anos. Destaca-se que segundo a estrutura de gestão universitária da IES, o corpo docente vinculado ao departamento de administração atende aos dois turnos e que os discentes do turno matutino podem cursar disciplinas no turno noturno e vice-versa. 
Em relação ao foco de interesse desta pesquisa, que é a oferta de conteúdos relacionados à ética, à RSC e à sustentabilidade, destaca-se que no turno matutino, com PPC atualizado em 2007, existem duas disciplinas obrigatórias que abordam o tema ética empresarial (ofertada no $7^{\circ}$ período) e gestão ambiental ( $5^{\circ}$ período). No turno noturno, com um PPC mais recente, de 2009, observou-se a presença das disciplinas ética empresarial ( $3^{\circ}$ período), gestão ambiental ( $6^{\circ}$ período) e a responsabilidade social e $3^{\circ}$ setor ( $5^{\circ}$ período). Além dessas, são ofertadas para os dois turnos disciplinas optativas ligadas ao tema, como por exemplo, gestão social e participativa, meio ambiente e desenvolvimento sustentável e sociologia e meio ambiente.

Considerando as características do curso, da estrutura de gestão universitária da IES, do perfil do egresso definido nos PPC e o objeto de investigação da pesquisa, optou-se neste estudo por tratar os dois turnos em conjunto. Com isso, os dados coletados, analisados e apresentados nas próximas subseções e seções do texto serão tratados coletivamente.

\subsection{DADOS SÓCIO DEMOGRÁFICOS}

A Tabela 1 apresenta o perfil sociodemográfico dos respondentes. Pode-se observar que a maioria é homem, estuda no turno matutino, está no meio do curso, é solteiro e possui entre 21 a 25 anos. Poucos alunos possuem outra graduação ou pós-graduação e a maior parte é estagiário ou não possui atividade profissional, embora quase $20 \%$ sejam empregados do setor privado. A maioria dos alunos também indica que já cursaram disciplinas no curso que trataram dos temas "moral e ética", "responsabilidade social" e "sustentabilidade".

Tabela 1 Dados sociodemográficos dos respondentes

\begin{tabular}{|c|c|c|c|c|c|}
\hline \multicolumn{3}{|l|}{ Sexo } & \multicolumn{3}{|c|}{ Possui pós-graduação } \\
\hline Masculino & 131 & $56,2 \%$ & Não & 229 & $98,3 \%$ \\
\hline Feminino & 102 & $43,8 \%$ & Sim (cursando/concluído) & 4 & $1,7 \%$ \\
\hline \multicolumn{3}{|l|}{ Turno } & \multicolumn{3}{|c|}{ Possui atividade profissional } \\
\hline Matutino & 135 & $57,9 \%$ & Não possuo & 75 & $32,2 \%$ \\
\hline Noturno & 98 & $42,1 \%$ & Estagiário & 76 & $32,6 \%$ \\
\hline \multicolumn{3}{|l|}{ Período } & Empregado (Privado) & 45 & $19,3 \%$ \\
\hline Início $\left(1^{\circ}, 2^{\circ}\right.$ e $\left.3^{\circ}\right)$ & 88 & $37,8 \%$ & Empregado/Servidor Público & 20 & $8,6 \%$ \\
\hline $\operatorname{Meio}\left(4^{\circ}, 5^{\circ}\right.$ e $\left.6^{\circ}\right)$ & 94 & $40,3 \%$ & Empresário/Autônomo & 17 & $7,3 \%$ \\
\hline $\operatorname{Fim}\left(7^{\circ}, 8^{\circ}\right.$ e $\left.9^{\circ}\right)$ & 51 & $21,9 \%$ & \multicolumn{3}{|c|}{ Já cursou "Moral e Ética" } \\
\hline \multicolumn{3}{|c|}{ Estado civil } & Não & 31 & $13,3 \%$ \\
\hline Solteiro & 209 & $89,7 \%$ & Sim (cursando) & 48 & $20,6 \%$ \\
\hline Casado/convive maritalmente & 24 & $10,3 \%$ & Sim (concluído) & 154 & $66,1 \%$ \\
\hline
\end{tabular}




\section{A SUSTENTABILIDADE NA PERSPECTIVA DE DISCENTES DE ADMINISTRAÇ̃̃O DE UMA UNIVERSIDADE PÚBLICA FEDERAL: NA PRÁTICA A SUSTENTABILIDADE FICA NO DISCURSO DOI: http://dx.doi.org/10.5007/1983-4535.2018v11n4p293}

\begin{tabular}{|c|c|c|c|c|c|}
\hline \multicolumn{3}{|c|}{ Faixa etária } & \multicolumn{3}{|c|}{ Já cursou "Responsabilidade Social" } \\
\hline De 16 até 20 & 84 & $36,1 \%$ & Não & 60 & $25,7 \%$ \\
\hline De 21 até 25 & 111 & $47,6 \%$ & Sim (cursando) & 54 & $23,2 \%$ \\
\hline De 26 até 30 & 22 & $9,4 \%$ & Sim (concluído) & 119 & $51,1 \%$ \\
\hline De 31 até 40 & 9 & $3,9 \%$ & \multicolumn{3}{|c|}{ Já cursou "Sustentabilidade" } \\
\hline Mais de 41 & 7 & $3,0 \%$ & \multirow{4}{*}{$\begin{array}{l}\text { Não } \\
\text { Sim (cursando) } \\
\text { Sim (concluído) }\end{array}$} & \multirow{2}{*}{$\begin{array}{l}84 \\
33\end{array}$} & $36,0 \%$ \\
\hline Possui outro cur: & ação & & & & $14,2 \%$ \\
\hline Não & 209 & $89,7 \%$ & & 116 & $49,8 \%$ \\
\hline Sim (cursando/concluído) & 24 & $10,3 \%$ & & & \\
\hline
\end{tabular}

Fonte: dados da pesquisa.

Do ponto de vista do objeto de pesquisa, destaca-se que o fato de a maioria dos respondentes ter cursado ou estar cursando as disciplinas relacionadas aos temas ética, RSC e sustentabilidade, é um indicativo positivo em relação a qualificação dos respondentes em participar da pesquisa. Ainda em relação a esta qualificação, destaca-se que a maioria dos respondentes $(67,8 \%)$ possui atividade profissional, seja como estagiário, como empregado (setor público ou privado) ou como empresário/autônomo.

\subsection{O PONTO DE VISTA DOS DISCENTES ACERCA DA SUSTENTABILIDADE}

As Tabelas 2, 3 e 4 apresentam os resultados das afirmativas sobre as dimensões econômicas, socioculturais e ambientais do TBL (ELKINGTON, 2012), respectivamente. Ressalta-se que os pontos 1 e 2 da escala Likert foram agrupados para representarem a noção de discordância, enquanto que os pontos 4 e 5 foram agrupados para representarem a noção de concordância. Dessa forma, o percentual de respondentes que assinalou o ponto 3 da escala Likert, que representa uma posição de indecisão quanto às afirmativas, não está presente nas tabelas. No entanto, pode-se auferir esse percentual por meio da diferença entre $100 \%$ e a soma dos percentuais dos respondentes que concordam e que discordam com as afirmativas.

A Tabela 2 apresenta as afirmativas sobre a dimensão econômica do TBL (ELKINGTON, 2012) levando em consideração um conjunto de stakeholders (PURNELL; FREEMAN, 2012) e a relação entre o comportamento esperado e o comportamento efetivo (SROUR, 1994). O conjunto de afirmativas abordado no questionário indicava sempre dois tipos de posicionamentos em relação a cada um dos stakeholders, sendo um baseado na ética da integridade (comportamento esperado) e outro baseado na ética do oportunismo (comportamento efetivo) (SROUR, 1994). Nesta dimensão, o foco foi na lucratividade (ELKINGTON, 2012; CIEGS et al., 2009; PIERANTONI, 2004). 
Tabela 2 Afirmativas acerca da dimensão econômica do triple bottom line (TBL)

\begin{tabular}{|c|c|c|c|}
\hline \multicolumn{4}{|c|}{ Painel A } \\
\hline Stakeholder & $\begin{array}{c}\text { Afirmativas que representam o comportamento } \\
\text { esperado }\end{array}$ & $\begin{array}{c}\text { Discorda } \\
\mathbf{m}\end{array}$ & $\begin{array}{c}\text { Concorda } \\
\mathbf{m}\end{array}$ \\
\hline Acionistas & $\begin{array}{l}\text { 1. O lucro de uma organização deve sempre ser distribuído } \\
\text { de forma equitativa entre os acionistas, os trabalhadores, a } \\
\text { sociedade e o meio ambiente. }\end{array}$ & $31,33 \%$ & $50,21 \%$ \\
\hline Empregados & $\begin{array}{l}\text { 15. A prática de distribuição de lucros para a classe } \\
\text { trabalhadora deve ser vista como um meio de justiça } \\
\text { social. }\end{array}$ & $18,88 \%$ & $54,08 \%$ \\
\hline Fornecedores & $\begin{array}{l}\text { 38. As organizações devem estabelecer relações } \\
\text { comerciais com fornecedores que sejam benéficas para } \\
\text { ambas as partes. }\end{array}$ & $5,15 \%$ & $85,41 \%$ \\
\hline $\begin{array}{l}\text { Consumidore } \\
\mathrm{s}\end{array}$ & $\begin{array}{l}\text { 28. Os consumidores devem ser vistos pelas organizações } \\
\text { como parceiros no desenvolvimento de soluções } \\
\text { vantajosas e a preço justo para ambas as partes. }\end{array}$ & $3,43 \%$ & $84,55 \%$ \\
\hline Concorrentes & $\begin{array}{l}\text { 32. As organizações devem estabelecer relações } \\
\text { mercadológicas cooperativas com a concorrência de forma } \\
\text { que todos possam atuar no mercado. }\end{array}$ & $21,03 \%$ & $53,65 \%$ \\
\hline Sociedade & $\begin{array}{l}\text { 30. O principal objetivo organizacional é gerar riqueza } \\
\text { para a sociedade, mesmo que tenha que privar o acionista } \\
\text { de lucros maiores. }\end{array}$ & $55,36 \%$ & $21,03 \%$ \\
\hline $\begin{array}{l}\text { Meio } \\
\text { Ambiente }\end{array}$ & $\begin{array}{l}\text { 42. Entre remunerar melhor os acionistas e adotar medidas } \\
\text { de proteção ambiental, as organizações devem privilegiar } \\
\text { investimentos que avancem em direção aos interesses } \\
\text { ambientais. }\end{array}$ & $11,59 \%$ & $63,52 \%$ \\
\hline \multicolumn{4}{|c|}{ Painel B } \\
\hline Stakeholder & Afirmativas que representam o comportamento efetivo & $\begin{array}{c}\text { Discorda } \\
\text { m }\end{array}$ & $\begin{array}{c}\text { Concorda } \\
\mathbf{m}\end{array}$ \\
\hline Acionistas & $\begin{array}{l}\text { 16. A prática organizacional cotidiana privilegia a } \\
\text { remuneração aos acionistas em detrimento de outras partes } \\
\text { interessadas, como por exemplo, os trabalhadores, a } \\
\text { sociedade e o meio ambiente. }\end{array}$ & $11,59 \%$ & $62,66 \%$ \\
\hline Empregados & $\begin{array}{l}\text { 36. As organizações adotam a prática de distribuição de } \\
\text { lucros como um mecanismo para obter maior } \\
\text { produtividade da classe trabalhadora. }\end{array}$ & $19,31 \%$ & $62,66 \%$ \\
\hline Fornecedores & $\begin{array}{l}\text { 6. Ao estabelecer relações comerciais com os } \\
\text { fornecedores, as organizações adotam políticas comerciais } \\
\text { voltadas para os resultados de curto prazo, que podem } \\
\text { comprometer a sobrevivência do fornecedor. }\end{array}$ & $22,75 \%$ & $39,06 \%$ \\
\hline $\begin{array}{l}\text { Consumidore } \\
\mathrm{s}\end{array}$ & $\begin{array}{l}\text { 13. As relações comerciais entre as organizações e os } \\
\text { consumidores é pautada por uma lógica em que ambas as } \\
\text { partes querem levar vantagem imediata. }\end{array}$ & $13,30 \%$ & $63,95 \%$ \\
\hline Concorrentes & $\begin{array}{l}\text { 41. Um dos principais objetivos das organizações é } \\
\text { eliminar a concorrência para alcançar uma maior fatia do } \\
\text { mercado. }\end{array}$ & $12,88 \%$ & $73,82 \%$ \\
\hline Sociedade & $\begin{array}{l}\text { 9. A sociedade é vista pelas organizações apenas como um } \\
\text { espaço para obter recursos e fornecer produtos e serviços } \\
\text { de forma lucrativa. }\end{array}$ & $26,18 \%$ & $53,65 \%$ \\
\hline
\end{tabular}




\begin{tabular}{llrl}
$\begin{array}{l}\text { Meio } \\
\text { Ambiente }\end{array}$ & $\begin{array}{l}\text { 18. As medidas de proteção ambiental são vistas pelas } \\
\text { organizações como um componente de despesa que } \\
\text { comprometem os lucros corporativos. }\end{array}$ & $18,45 \%$ & $\mathbf{6 0 , 5 2 \%}$ \\
\hline
\end{tabular}

Fonte: dados da pesquisa.

Considerando a perspectiva conceitual da sustentabilidade (ELKINGTON, 2012; CIEGS et al., 2009; PIERANTONI, 2004), assumiu-se no estudo que as dimensões econômicas, sociocultural e ambiental são tratadas de forma equitativa considerando a perspectiva de longo prazo por envolver as gerações futuras. Partindo-se desta premissa, os resultados apresentados na Tabela 2 indicam que o comportamento esperado é orientado para a sustentabilidade e o longo prazo e o comportamento efetivo é orientado para a lógica oportunista e de curto prazo (ELKINGTON, 2012; CIEGS et al., 2009; PIERANTONI, 2004; SROUR, 1994).

Porém, dois resultados em especial merecem reflexões. O primeiro diz respeito ao comportamento esperado em relação à sociedade. Para os respondentes, a geração de riqueza das organizações somente pode ser alcançada depois que o acionista obteve o lucro, ou seja, a lucratividade do acionista é mais importante que o bem-estar da sociedade. Há neste caso, um indicativo de que a lógica oportunista orienta o comportamento esperado dos respondentes.

O segundo aspecto, está relacionado ao comportamento efetivo em relação aos fornecedores. Nesse ponto, identificou-se o menor percentual de concordância $(39,06 \%)$, sugerindo a presença de uma maioria de indecisos e/ou que não concordam que as organizações adotem políticas comerciais em que a sua lucratividade possa comprometer a sobrevivência de fornecedores. Considerando que os fornecedores representam parceiros comerciais relevantes para as organizações (PIRES, 2009; COUSINS et al., 2008), a possibilidade de comprometimento de sua sobrevivência demonstra um indicativo de viés sustentável (ELKINGTON, 2012; CIEGS et al., 2009; PIERANTONI, 2004) no ponto de vista dos respondentes no que concerne à relação da organização com os fornecedores.

A Tabela 3 apresenta as afirmativas sobre a dimensão sociocultural do TBL (ELKINGTON, 2012). O foco de interesse envolve o bem-estar social, os direitos humanos, os valores culturais, entre outros (ELKINGTON, 2012; CIEGS et al., 2009; PIERANTONI, 2004). 
Tabela 3 Afirmativas acerca da dimensão sociocultural do triple bottom line (TBL)

\begin{tabular}{|c|c|c|c|}
\hline \multicolumn{4}{|c|}{ Painel A } \\
\hline Stakeholder & $\begin{array}{c}\text { Afirmativas que representam o comportamento } \\
\text { esperado }\end{array}$ & Discordam & Concordam \\
\hline Acionistas & $\begin{array}{l}\text { 20. As organizações devem incluir interesses de } \\
\text { outros públicos, além de acionistas, em seu } \\
\text { planejamento estratégico. }\end{array}$ & $10,73 \%$ & $70,82 \%$ \\
\hline Empregados & $\begin{array}{l}\text { 2. As organizações devem minimizar os riscos e } \\
\text { impactos aos direitos humanos que causam, como por } \\
\text { exemplo, impactos na saúde e bem-estar de } \\
\text { empregados próprios e terceiros. }\end{array}$ & $2,15 \%$ & $92,27 \%$ \\
\hline Fornecedores & $\begin{array}{l}\text { 27. As organizações não devem comprar bens ou } \\
\text { serviços de fornecedores que violem os direitos } \\
\text { humanos. }\end{array}$ & $9,44 \%$ & $80,69 \%$ \\
\hline Consumidores & $\begin{array}{l}\text { 21. Os consumidores devem ter os seus valores, } \\
\text { crenças e símbolos culturais respeitados pelas } \\
\text { organizações. }\end{array}$ & $3,86 \%$ & $83,69 \%$ \\
\hline Concorrentes & $\begin{array}{l}\text { 19. As organizações devem disponibilizar para a } \\
\text { concorrência informações sobre a sua estratégia de } \\
\text { investimentos sociais. }\end{array}$ & $45,92 \%$ & $31,33 \%$ \\
\hline Sociedade & $\begin{array}{l}\text { 39. As organizações devem manter iniciativas de } \\
\text { diálogo e engajamento com as partes interessadas } \\
\text { (público interno, governo, ONG e comunidade). }\end{array}$ & $4,72 \%$ & $81,55 \%$ \\
\hline Meio Ambiente & $\begin{array}{l}\text { 37. As organizações devem participar constantemente } \\
\text { de fóruns e encontros promovidos por representantes } \\
\text { do meio ambiente. }\end{array}$ & $9,01 \%$ & $72,53 \%$ \\
\hline
\end{tabular}

\begin{tabular}{|c|c|c|c|}
\hline \multicolumn{4}{|c|}{ Painel B } \\
\hline Stakeholder & $\begin{array}{c}\text { Afirmativas que representam o comportamento } \\
\text { efetivo }\end{array}$ & Discordam & Concordam \\
\hline Acionistas & $\begin{array}{l}\text { 22. Os direcionadores do planejamento estratégico } \\
\text { das organizações estão baseados nos interesses dos } \\
\text { acionistas. }\end{array}$ & $9,87 \%$ & $68,67 \%$ \\
\hline Empregados & $\begin{array}{l}\text { 10. Os riscos e impactos na saúde e bem-estar de } \\
\text { empregados próprios e terceiros são sempre } \\
\text { gerenciados de forma a minimizar os custos } \\
\text { operacionais. }\end{array}$ & $20,17 \%$ & $52,36 \%$ \\
\hline Fornecedores & $\begin{array}{l}\text { 12. Os fornecedores são contratados pela lógica do } \\
\text { menor preço, mesmo que tenham práticas que violem } \\
\text { os direitos humanos. }\end{array}$ & $35,62 \%$ & $42,06 \%$ \\
\hline Consumidores & $\begin{array}{l}\text { 4. As organizações procuram impor seus valores, } \\
\text { crenças e símbolos culturais aos consumidores como } \\
\text { uma estratégia de fidelização de clientes. }\end{array}$ & $12,45 \%$ & $66,09 \%$ \\
\hline Concorrentes & $\begin{array}{l}\text { 29. As organizações não divulgam informações sobre } \\
\text { investimentos sociais por receio de serem imitadas ou } \\
\text { superadas pela concorrência. }\end{array}$ & $24,89 \%$ & $46,35 \%$ \\
\hline Sociedade & $\begin{array}{l}\text { 35. As organizações se relacionam com as partes } \\
\text { interessadas (público interno, governo, ONG e } \\
\text { comunidade) de forma a obter vantagem econômica } \\
\text { nessa relação. }\end{array}$ & $9,01 \%$ & $70,82 \%$ \\
\hline
\end{tabular}




\section{O meio ambiente é visto pelas organizações}

Meio Ambiente somente como uma fonte de recursos naturais para viabilizar suas ações produtivas e comerciais.

Fonte: dados da pesquisa.

Semelhante ao que ocorreu com a dimensão econômica do TBL, a análise dos resultados da Tabela 3 indica que o comportamento esperado é orientado para a sustentabilidade e o longo prazo e o comportamento efetivo é orientado para a lógica oportunista e de curto prazo (ELKINGTON, 2012; CIEGS et al., 2009; PIERANTONI, 2004; SROUR, 1994). Porém, diferentemente do que se observou com os resultados da dimensão econômica, nesta dimensão sociocultural foi possível constatar um sentido de sobrevivência organizacional.

Para os respondentes, na relação da organização com os seus concorrentes, o comportamento esperado é ancorado numa lógica utilitarista e de curto prazo, em que as organizações não devem fornecer informações aos concorrentes de seus investimentos sociais. Esse ponto de vista é confirmado quando os respondentes indicam a mesma lógica em relação ao comportamento efetivo ao assumirem que para não serem imitadas ou mesmo superada pelos concorrentes, as organizações não divulgam informações de seus investimentos sociais para os concorrentes. Neste caso, a transparência na divulgação das ações e investimentos sociais da organização para a sociedade estaria comprometida (NOVELINE; FREGONESI, 2013).

A Tabela 4 apresenta afirmativas sobre a dimensão ambiental do TBL (ELKINGTON, 2012). O interesse é abordar aspectos relacionados ao meio ambiente, à natureza e aos ecossistemas locais (ELKINGTON, 2012; CIEGS et al., 2009; PIERANTONI, 2004).

Tabela 4 Afirmativas acerca da dimensão ambiental do triple bottom line (TBL)

\section{Painel A}

\begin{tabular}{|c|c|c|c|}
\hline Stakeholder & $\begin{array}{c}\text { Afirmativas que representam o comportamento } \\
\text { esperado }\end{array}$ & Discordam & Concordam \\
\hline Acionistas & $\begin{array}{l}\text { 34. As questões ambientais devem ser tratadas com o } \\
\text { mesmo nível de atenção que o lucro é tratado pelos } \\
\text { acionistas. }\end{array}$ & $10,30 \%$ & $75,54 \%$ \\
\hline Empregados & $\begin{array}{l}\text { 31. As organizações devem implementar práticas de } \\
\text { recursos humanos orientadas para a questão } \\
\text { ambiental. }\end{array}$ & $3,86 \%$ & $80,69 \%$ \\
\hline Fornecedores & $\begin{array}{l}\text { 3. As organizações devem dar preferência à compra } \\
\text { de insumos ou serviços ambientalmente sustentáveis. }\end{array}$ & $2,58 \%$ & $87,98 \%$ \\
\hline
\end{tabular}




\begin{tabular}{|c|c|c|c|}
\hline Consumidores & $\begin{array}{l}\text { 8. As organizações devem lançar medidas para } \\
\text { incentivar e sensibilizar o consumidor a encaminhar } \\
\text { os resíduos gerados para reciclagem de volta para as } \\
\text { organizações. }\end{array}$ & $3,43 \%$ & $89,70 \%$ \\
\hline Concorrentes & $\begin{array}{l}\text { 23. As organizações devem promover parcerias com } \\
\text { os concorrentes para preservar o meio ambiente. }\end{array}$ & $6,87 \%$ & $74,68 \%$ \\
\hline Sociedade & $\begin{array}{l}\text { 26. As organizações devem incentivar a sociedade no } \\
\text { desenvolvimento de uma cultura ambientalmente } \\
\text { sustentável. }\end{array}$ & $3,43 \%$ & $86,70 \%$ \\
\hline Meio Ambiente & $\begin{array}{l}\text { 11. As organizações devem adotar políticas de } \\
\text { proteção e preservação ambiental em todas as suas } \\
\text { atividades. }\end{array}$ & $5,58 \%$ & $88,84 \%$ \\
\hline \multicolumn{4}{|c|}{ Painel B } \\
\hline Stakeholder & $\begin{array}{c}\text { Afirmativas que representam o comportamento } \\
\text { efetivo }\end{array}$ & Discordam & Concordam \\
\hline Acionistas & $\begin{array}{l}\text { 7. As questões ambientais somente são consideradas } \\
\text { se não houver o comprometimento da lucratividade } \\
\text { para o acionista. }\end{array}$ & $30,47 \%$ & $51,93 \%$ \\
\hline Empregados & $\begin{array}{l}\text { 40. As políticas e práticas de recursos humanos } \\
\text { adotadas pelas organizações alcançam a questão } \\
\text { ambiental desde que não comprometam a } \\
\text { produtividade. }\end{array}$ & $9,44 \%$ & $66,09 \%$ \\
\hline Fornecedores & $\begin{array}{l}\text { 33. Os fornecedores são contratados pela lógica do } \\
\text { menor preço, mesmo que comprometam o meio } \\
\text { ambiente. }\end{array}$ & $25,75 \%$ & $54,51 \%$ \\
\hline Consumidores & $\begin{array}{l}\text { 17. Para viabilizar o menor preço para os } \\
\text { consumidores, as organizações reduzem } \\
\text { investimentos de natureza ambiental. }\end{array}$ & $19,74 \%$ & $58,37 \%$ \\
\hline Concorrentes & $\begin{array}{l}\text { 5. Entre vencer a concorrência e ser ambientalmente } \\
\text { sustentável, as organizações optam pela liderança de } \\
\text { mercado. }\end{array}$ & $6,01 \%$ & $\mathbf{7 8 , 9 7 \%}$ \\
\hline Sociedade & $\begin{array}{l}\text { 25. As organizações investem em políticas ambientais } \\
\text { que favorecem a sociedade somente se houver retorno } \\
\text { financeiro. }\end{array}$ & $15,02 \%$ & $63,52 \%$ \\
\hline Meio Ambiente & $\begin{array}{l}\text { 14. As organizações somente adotam medidas } \\
\text { corretivas quando causam impactos ambientais } \\
\text { negativos. }\end{array}$ & $20,17 \%$ & $61,80 \%$ \\
\hline
\end{tabular}

Fonte: dados da pesquisa.

No caso específico desta dimensão ambiental do TBL, observou-se para todas as afirmativas que, o comportamento esperado é orientado pela lógica da sustentabilidade e para o longo prazo, e que o comportamento efetivo é orientado pela lógica oportunista, utilitarista e de curto prazo (ELKINGTON, 2012; CIEGS et al., 2009; PIERANTONI, 2004; SROUR, 1994). Em outros termos, para os respondentes, as preocupações com o meio ambiente ficam apenas no discurso. Isso pelo fato de aspectos como a lucratividade para o acionista, a produtividade e a competição prevalecerem frente aos aspectos ambientais. 


\section{A SUSTENTABILIDADE NA PERSPECTIVA DE DISCENTES DE ADMINISTRAÇ̃̃O DE UMA \\ UNIVERSIDADE PÚBLICA FEDERAL: NA PRÁTICA A SUSTENTABILIDADE FICA NO DISCURSO \\ DOI: http://dx.doi.org/10.5007/1983-4535.2018v11n4p293}

\section{CONCLUSÃO}

Pretendeu-se com este estudo identificar o ponto de vista de discentes em administração acerca da noção de sustentabilidade. Para isso, aplicou-se uma pesquisa survey (BABBIE, 2005) junto aos discentes do curso de graduação de uma universidade pública federal localizada na região sudeste do Brasil. Os dados foram coletados por meio de triangulação (DENZIN, 1989; JICK, 1979) ao articular pesquisa documental e aplicação de questionário junto a uma amostra probabilística de 233 discentes matriculados nos turnos matutino e noturno.

A síntese dos resultados indica que a sustentabilidade na prática fica no discurso. Isso pelo fato dos respondentes, em sua maioria, demonstrarem altos níveis de concordância com a lógica sustentável e de longo prazo (ELKINGTON, 2012; CIEGS et al., 2009; PIERANTONI, 2004) quando se referiam ao comportamento esperado e indicavam altos níveis de concordância com a lógica oportunista, utilitarista e de curto prazo (SROUR, 1994) quando se referiam ao comportamento efetivo. Com isso, pode-se inferir que, para os respondentes, aspectos como a lucratividade para o acionista, a produtividade e a competição, prevalecem frente aos aspectos socioculturais e ambientais. Os resultados refletem os conflitos e os tradeoffs existentes dada a natureza multifacetada e complexa da sustentabilidade (HANN et al., 2015, 2010).

Essas duas lógicas apresentaram diferenças somente em três situações. Na primeira, ao tratarem da dimensão econômica, os respondentes indicaram em seu comportamento esperado que a lucratividade do acionista prevalece sobre os interesses da sociedade. Neste caso, houve uma manifestação de que a lógica do discurso está alinhada com a dimensão prática, ou seja, os respondentes assumem que o que prevalece é a dimensão econômica sobre as demais dimensões de sustentabilidade (ELKINGTON, 2012).

$\mathrm{Na}$ segunda situação, também relacionada com a dimensão econômica, os respondentes indicaram em seu comportamento efetivo que o trato dos fornecedores possui um viés sustentável (ELKINGTON, 2012; CIEGS et al., 2009; PIERANTONI, 2004). Observou-se a indicação de uma maioria de indecisos e discordantes de que as organizações possam comprometer a sobrevivência dos fornecedores em detrimento da lucratividade, ou seja, se tiverem que escolher entre a lucratividade do acionista e a sobrevivência dos fornecedores, os respondentes optaram pelos fornecedores. Uma possível explicação para esta situação pode estar relacionada ao fato dos respondentes reconhecerem nos fornecedores um 


\section{A SUSTENTABILIDADE NA PERSPECTIVA DE DISCENTES DE ADMINISTRAÇÃO DE UMA \\ UNIVERSIDADE PÚBLICA FEDERAL: NA PRÁTICA A SUSTENTABILIDADE FICA NO DISCURSO \\ DOI: http://dx.doi.org/10.5007/1983-4535.2018v11n4p293}

parceiro comercial/empresarial relevante das organizações (PIRES, 2009; COUSINS et al., 2008).

$\mathrm{Na}$ terceira situação, ao tratarem da dimensão sociocultural os respondentes indicaram em seu comportamento esperado que, por uma questão de sobrevivência, as organizações não fornecem informações de seus investimentos sociais para a concorrência. Neste caso, assumese que a lógica oportunista, utilitarista e de curto prazo se faz presente também no discurso dos respondentes. Nesse sentido, para os respondentes as organizações estariam comprometendo a transparência na divulgação das ações e investimentos sociais (NOVELINE; FREGONESI, 2013) e, consequentemente, a sua prestação de contas para com a sociedade.

A síntese dos resultados indica para a necessidade de se repensar a forma como a sustentabilidade tem sido tratada nos cursos de administração. Conforme apontam Jacobi et al. (2011), as IES e os cursos de administração tem abordado a questão da sustentabilidade de uma forma exógena e reativa, ao cederem a pressões para discutir essa temática e suas implicações para a sociedade. De fato, como defendem Hourneaux Junior et al. (2014) e Gonçalves-Dias et al. (2013), a abordagem da sustentabilidade deve seguir a um processo inverso, ou seja, que as IES, de forma endógena, assumam para si a cultura e a institucionalização (SCHVARSTEIN, 1995) da sustentabilidade e a pratiquem de forma efetiva na dinâmica institucional e no ensino.

Com isso, defende-se neste artigo que, somente após assumir a sustentabilidade de forma transversal e transdisciplinar e por meio de uma abordagem holística, de integração e de síntese (VASCONCELOS et al., 2013; SENGE et al., 2009; ALMEIDA, 2008; 2002; ANTONELLO, 2005), é que o processo de ensino e a aprendizagem produzirá resultados diferentes no ponto de vista dos discentes de administração e futuros gestores. Esta diferença de ponto de vista tende a ser favorável à aproximação do discurso e da prática, de forma que a sustentabilidade seja efetivamente praticada pelas organizações e pela sociedade.

Espera-se que os resultados aqui apresentados possam indicar caminhos para que gestores universitários, gestores de políticas públicas e empresários reflitam sobre a necessidade de adotar uma visão e uma abordagem orientada para a sustentabilidade em que a perspectiva holística, de integração e de síntese norteie o processo de formação educacional nos cursos de graduação em administração, inclusive na postura das instituições, de forma a se refletir nas tomadas de decisões de negócios posteriormente. Considera-se essas questões 
essenciais para a construção de uma sociedade melhor, mais justa, socialmente responsável e sustentável.

\section{REFERÊNCIAS}

ALCADIPANI, R.; CALDAS, M. P. Americanizing Brazilian management. Critical Perspectives on International Business, [S.1.], v. 8, n. 1, p. 37-55, 2012.

ALMEIDA, F. Os desafios da sustentabilidade: uma ruptura urgente. Rio de Janeiro: Campus Elsevier, 2008.

ALMEIDA, F. O bom negócio da sustentabilidade. São Paulo: Nova Fronteira, 2002

ANTONELLO, C. S. Desenvolvimento de recursos humanos e a aprendizagem no local de trabalho: identificando perspectivas e abordagens. In: SEMINÁRIOS EM

ADMINISTRAÇÃO, 8., 2005, São Paulo. Anais..., São Paulo: FEA/USP, 2005.

BABBIE, E. Métodos de pesquisas de survey. Belo Horizonte: Editora UFMG, 2005.

BOAVA, D. L. T.; BOAVA, F. M. F. M.; SETTE, R. S. Meditações funcionalistas: cinco reflexões sobre a administração. Revista Administração em Diálogo, São Paulo, v. 16, n. 1, p. 82-104, 2014.

BRASIL Lei $\mathrm{n}^{\circ}$ 4.769, de 9 de setembro de 1965. Dispõe sobre o exercício da profíssão de Técnico de Administração, e dá outras providências. Diário Oficial [da] República

Federativa do Brasil, Brasília, 13 de setembro de 1965, Seção 1, p.9337.

CIEGIS, R.; RAMANAUSKIENE, J.; MARTINKUS, B. The concept of sustainable development and its use for sustainability scenarios. Engineering Economics, [S.1.], n. 2, p. 28-37, 2009.

CONSELHO NACIONAL DA EDUCAÇÃO. Resolução no 4, de 13 de julho de 2005. Institui as Diretrizes Curriculares Nacionais do Curso de Graduação em Administração, bacharelado, e dá outras providências. Diário Oficial [da] República Federativa do Brasil, Brasília, 19 de julho de 2005, Seção 1, p. 26.

COUSINS, P.; LAMMING, R.; LAWSON, B.; SQUIRE, B. Strategic supply management: principles, theories and practice. England: Pearson Education, 2008.

DENZIN, N. The research act: a theoretical introduction to sociological methods. 3. ed. New York, NY: Prentice Hall, 1989.

EKINS, P.; SIMON, S.; DEUTSCH, L.; FOLKE, C.; Groot, R. D. A Framework for the practical application of the concepts of critical natural capital and strong sustainability. Ecological Economics, [S.1.], v. 44, n. 2-3, p. 165-185, 2003.

ELKINGTON, J. Sustentabilidade: canibais com garfo e faca. São Paulo: MBooks, 2012. 
FÁVERO, L. P.; BELFIORE, P.; SILVA, F. L.; CHAN, B. L. Análise de dados: modelagem multivariada para tomada de decisões. Rio de Janeiro: Elsevier, 2009.

FERGUS, A. H. T.; ROWNEY, J. I. A. Sustainable development: lost meaning and opportunity? Journal of Business Ethics, [S.1.], v. 60, n. 1, p. 17-27, 2005.

FEU, K. S.; KOMINO, A. C.; SILVA JUNIOR, A. da; SILVA, V. C. da ; VEIGA, R.; VAGO, J. G. R. Responsabilidade social corporativa na perspectiva de discentes de administração: a inversão da pirâmide. In: CONGRESSO BRASILEIRO DE ESTUDOS ORGANIZACIONAIS, 4., 2016, Porto Alegre. Anais... Brasil: SBEO, 2016.

GONÇALVES-DIAS, S. L. F.; HERRERA, C. B.; CRUZ, M. T. S. Desafios (e dilemas) para inserir "sustentabilidade" nos currículos de administração: um estudo de caso. Revista de Administração Mackenzie, São Paulo. v. 14, n. 3, p. 119-153, 2013.

HANN, T.; PINKSE, J.; PREUSS, L.; FIGGE, F. Tensions in corporate sustainability: towards an integrative framework. Journal of Business Ethics, [S.1.], v. 127, n. 2, p. 297 $316,2015$.

HANN, T.; FIGGE, F.; PINKSE, J.; PREUSS, L. Trade-offs in corporate sustainability: you can't have your cake and eat it. Business Strategy and the Environment, [S.1.], v. 19, n. 4, p. 217-229, 2010.

HOURNEAUX JUNIOR, F.; DIAS, B. G.; ZELLMEISTER, L. M.; BRINHOLI, C. F. A Sustentabilidade no ensino de administração: proposta de um currículo básico para o curso de graduação. In: ENCONTRO NACIONAL DA ASSOCIAÇÃO NACIONAL DE PÓSGRADUAÇÃO E PESQUISA EM ADMINISTRAÇÃO, 38., 2014, Rio de Janeiro. Anais... Rio de Janeiro: ANPAD, 2014.

JACOBI, P. R.; RAUFFLET, E.; ARRUDA, M. P. Educação para a sustentabilidade nos cursos de administração: reflexão sobre paradigmas e práticas. Revista de Administração Mackenzie, São Paulo, v. 12, n. 3, p. 21-50, 2011.

JICK, T. D. Mixing qualitative and quantitative methods: triangulation in action.

Administrative Science Quarterly, [S.1.], v.24, n.4, 1979.

LELE, S. Sustainable development: a critical review. World Development, [S.1.], v. 19, n. 6, p. 607-621, 1991.

LE ROUX, C.; PRETORIUS, M. Navigating sustainability embeddedness in management decision-making. Sustainability, [S.1.], v. 8, n. 5, p. 444, 2016.

LEVINE, D.; STEPHAN, D. F.; KREHBLEL, T.; BERENSON, M. L. Estatística: teoria e aplicações 6. ed. Rio de Janeiro: LTC, 2015.

MEBRATU, D. Sustainability and sustainable development: historical and conceptual review. Environmental Impact Assessment Review, [S.1.], v. 18, n. 6, p. 493-520, 1998. 
MÜLLER, A. L.; PFLEGER, R. Business transformation towards sustainability. Business Research, [S.1.], v. 7, n. 2, p. 313-350, 2014.

NOVELINI, C. P.; FREGONESI, M. F. S. A. Análise da divulgação de informações sobre investimentos sociais por empresas que se declaram socialmente responsáveis. Revista de Contabilidade e Organizações - USP, São Paulo, v. 7, n. 17, p. 90-101, 2013.

PAUL, B. D. A history of the concept of sustainable development: literature review. Annals of the University of Oradea, Economic Sciences Series, [S.1], v. 17, n. 2, p. 576-580, 2008. PIERANTONI, I. A. Few remarks on methodological aspects related to sustainable development. In: OECD. Measuring sustainable development: integrated economic, environmental and social frameworks. [S.1.]: OECD Publishing. 2004. p. 63-89.

PIRES, S. R. I. Gestão da cadeia de suprimentos (supply chain management): conceitos, estratégias, práticas e casos. 2. ed. São Paulo: Atlas, 2009.

PURNELL, L. S.; FREEMAN, R. E. Stakeholder theory, fact/value dichotomy, and the normative core: how Wall Street stop the ethics conversation. Journal of Business Ethics, [S.1], v. 109, p. 109-116, 2012.

SACHS, J. A riqueza de todos: a construção de uma economia sustentável em um planeta superpovoado, poluído e pobre. Rio de Janeiro: Nova Fronteira, 2008.

SARTORI, S.; LATRONICO, F.; CAMPOS, L. M. S. Sustentabilidade e desenvolvimento sustentável: uma taxonomia no campo da literatura. Ambiente \& Sociedade, [S.1.], v. 17, n. 1, p. 1-22, 2014.

SCHVARSTEIN, L. Psicologia social de las organizaciones: nuevos aportes. Buenos Aires: Paidós, 1995.

SENGE, P.; SMITH, B.; KRUSCHWITZ, N.; SCHLEY, S.; LAUR, J. A Revolução decisiva: como indivíduos e organizações trabalham em parceria para criar um mundo sustentável. Tradução de Afonso Celso da Cunha Serra. Rio de Janeiro: Campus Elsevier, 2009.

SILVA JUNIOR, A. da; POLIZEL, C. E. G.; SOUZA, S.; SILVA, A. R. L. da; SILVA, P. O. M. da; SOUZA, S. P. de. Políticas públicas para a educação superior: a avaliação, a regulação e a supervisão de IES privadas em debate. Ensaio (Fundação Cesgranrio), Rio de Janeiro, v. 22, p. 215-240, 2014.

SROUR, R. H. Ética empresarial sem moralismo. Revista de Administração da USP, São Paulo, v. 29, n. 3, p. 3-22, 1994.

VASCONCELOS, K. C. de A.; SILVA JUNIOR, A. da; SILVA, P. de O. M. da. Educação gerencial para atuação em ambientes de negócios sustentáveis: desafios e tendências de uma escola de negócios brasileira. Revista de Administração Mackenzie, São Paulo, v. 14, n. 4, p. 45-75, 2013. 